\title{
A SHARP UNCERTAINTY PRINCIPLE AND HARDY-POINCARÉ INEQUALITIES ON SUB-RIEMANNIAN MANIFOLDS
}

\author{
Semra Ahmetolan And Ismail Kombe
}

Abstract. We prove a sharp Heisenberg uncertainty principle inequality and Hardy-Poincaré inequality on the sub-Riemannian manifold $\mathbb{R}^{2 n+1}=\mathbb{R}^{n} \times \mathbb{R}^{n} \times \mathbb{R}$ defined by the vector fields:

$$
X_{j}=\frac{\partial}{\partial x_{j}}+2 k y_{j}|z|^{2 k-2} \frac{\partial}{\partial l}, \quad Y_{j}=\frac{\partial}{\partial y_{j}}-2 k x_{j}|z|^{2 k-2} \frac{\partial}{\partial l}, \quad j=1,2, \ldots, n
$$

where $|z|=\left(|x|^{2}+|y|^{2}\right)^{1 / 2}$ and $k \geqslant 1$.

Mathematics subject classification (2010): 22E30, 43A80, 26 D10.

Keywords and phrases: Hardy-Poincaré inequality, Uncertainty principle inequality.

\section{REFERENCES}

[1] S. Ahmetolan, Nonlinear Degenerate Parabolic Equations with Singular Coefficients for Greiner Vector Fields, Applicable Analysis, 87, No. 7 (2008), 741-754.

[2] S. Ahmetolan and S. Cavdar, Nonlinear Degenerate Parabolic Equations with Time Dependent Singular Coefficients, Math. Nachr., DOI 10.1002/mana.200810135, (2011).

[3] S. Ahmetolan And I. Kombe, Rellich Type Inequalities on Sub-Riemannian Manifolds, preprint.

[4] J. G. Azorero And I. P. Alonso, Hardy inequalities and some critical elliptic and parabolic problems, J. Diff. Equations, 144 (1998), 441-476.

[5] P. BARAs J. A. And GoldsteIn, The heat equation with a singular potential, Trans. AMS, 284 (1984), 121-139.

[6] R. Beals, B. Gaveau, P. Greiner and J. Vauthier, The Laguerre Calculus on the Heisenberg group: II, Bull. Sci. Math. 110 (1986), 225-288.

[7] R. BEAls, B. GAVEAU AND P. GREINER, On a geometric formula for the fundamental solution of subelliptic Laplacians, Math. Nachr. 181 (1996), 81-163.

[8] R. Beals, B. Gaveau, And P. Greiner, Uniform hypoelliptic Green's functions, J. Maths. Pures Appl. 77 (1998), 209-248.

[9] R. BEALs, B. GAVEAU AND P. GREINER, Green's fnctions for some highly degenerate elliptic operators, J. Funct. Anal., 165 (1999), 407-429.

[10] X. CABRÉ AND Y. MARTEL, Existence versus explosion instantanée pour des équations de la chaleur linéaires avec potentiel singulier, C. R. Acad. Sci. Paris, 329 (1999), 973-978.

[11] O. Calin, D. C. Chang And P. Greiner, Geometric Analysis on the Heisenberg Group and Its Generalizations, AMS/IP Series in Advanced Mathematics, 40, American Mathematics Society and International Press, Cambridge, MA (2007)

[12] O. CALIN, On a Step 2( $k+1)$ Sub-Riemannian. Manifold, Journal of Geometric Analysis. Volume 14, Number 1, 2004.

[13] P. GReINer, A fundamental solution for non-elliptic partial differential operator, Can. J. Math. 31 (1979), 1107-1120.

[14] G. B. Folland And A. Sitaram, The Uncertainty Principle: A Mathematical Survey, The Journal of Fourier Analysis and Applications, 3, No. 3 (1997), 207-238.

[15] J. A. Goldstein AND I. KOMBE, Nonlinear parabolic differential equations with the singular lower order term, Adv. Differential Equations 10 (2003), 1153-1192. 
[16] J. A. Goldstein AND I. Kombe, Instantaneous blow up, Contemp. Math. 327 (2003) 141-149.

[17] J. A. Goldstein AND I. KomBe, The Hardy inequality and nonlinear parabolic equations on Carnot group, Nonlinear Analysis, 69, No. 12 (2008) 4643-4653.

[18] W. HeISENBERG, Über den anschaulichen Inhalt der quantentheoretischen Kinematik und Mechanik, Z. Physik 43 (1927), 172-198.

[19] L. HÖRMANDER, Hypoelliptic second order differential equations, Acta Math. 119(1967), 147-171.

[20] I. Kомве, The linear heat equation with a highly singular, oscillating potential, Proc. Amer. Math. Soc. 132 (2004), 2683-2691.

[21] I. KomBE, Cauchy-Dirichlet Problem for the nonlinear degenerate parabolic equations, Abstract and Applied Analysis, 6, (2005), 607-617.

[22] I. KomBE, On the nonexistence of positive solutions to nonlinear degenerate parabolic equations with singular coefficients, Applicable Analysis, 85, No. 5 (2006), 467-478.

[23] P. Niu, H. Zhang, Y. WANG, Hardy-type inequalities and Pohozaev-type identities for a class of p-degenerate subelliptic operators and applications, Nonlinear Analysis, 54 (2003), 165-186

[24] P. Niu, Y. OU AND J. HAN, Several Hardy type inequalities with Weights related to generalized greiner operator, Canadian Math. Bulletin, doi:10.4153/CMB-2010-029-9. 